\title{
Green Logistics: \\ The Way to Environmental Sustainability of Logistics. Empirical Evidence from Polish SMEs
}

\author{
By Krzysztof Zowada ${ }^{1}$
}

\begin{abstract}
The needs related to natural environment protection, which are accentuated both in world literature and practice, became the main prerequisite to find new management concepts enabling the development of solutions which are environmentally responsible and economically effective at the same time. One of the concepts which can be an answer for the requirements related to environment protection is the 'green logistics' concept. The literature review shows that publications referring to the development of 'green logistics' have so far focused primarily on the processes of implementation and development of 'green logistics' in large enterprises. In other words, the reviewed research studies didn't take into account the specific nature of the SME sector, which is a very important factor considering its diversity and, most of all, its high significance and size in the economy. As a consequence, a research gap related to the development of 'green logistics' among small and medium-sized enterprises was identified. To explore the identified research gap, a survey among 200 SMEs running their businesses in Poland was conducted. On the basis of the conducted research, it was revealed that SMEs' activities related to environment protection when running logistics processes are mostly determined by actual legal provisions. However, this amounts to enterprises reaching a certain minimum related to the state's environmental policy. On the other hand, it's worth emphasising the role of the supply chain leader, which becomes a strong driving force for implementing 'green' solutions in the area of logistics for enterprises with higher levels of 'green logistics' development. The research results can be a starting point for creating a model illustrating the development of 'green logistics' in the SME sector.
\end{abstract}

Keywords: green logistics, environmental sustainability, SME

\section{Introduction}

The needs related to natural environment protection, which are accentuated both in world literature and practice, became the main prerequisite for finding new management concepts enabling the development of solutions which are environmentally responsible and economically effective at the same time. Increasingly, decisions taken by enterprises at various levels of management take into account both economic and ecological criteria. This is related not only to the current 'fashion', but, above all, the need to meet the expectations of various groups of stakeholders (including government, NGOs, society, competitors, customers etc.).

In response to the conditions in which today's enterprises have to function, in the area of logistics new concepts are also being developed to improve the material and information flows. One of the concepts which can be an answer for the requirements related to environment protection is the 'green logistics' concept. A great simplification is that 
'green logistics' enable the formation of logistics systems which are both environmentally responsible and economically effective. It can, therefore, be said that it is a proposal to solve one of the important problems facing enterprises in the 21 st century.

The literature review shows that publications referring to the development of 'green logistics' have so far focused primarily on the processes of implementation and development of 'green logistics' in large enterprises. In other words, the reviewed research studies didn't take into account the specific nature of the SME sector, which is a very important factor considering its diversity and, most of all, its high significance and size in the national economy. ${ }^{1}$ As a consequence, a research gap related to the development of 'green logistics' among small and medium-sized enterprises was identified.

In Poland, the 'green logistics' concept is a relatively underdeveloped concept in the literature, however, in practice, numerous examples of its implementation can be found. Long-term observation of the activity of small and medium-sized enterprises revealed the increasing influence of environment protection issues, in a broad sense, on the logistics decisions being made by those entities. Among the examples of such decisions, one can indicate the selection of transport options meeting high standards of fumes emissions, implementing multi-use packages, etc. Therefore, it's worth asking the question: what determines the development of 'green logistics' in small and mediumsized enterprises in Poland?

In view of the research question formulated in this way, the aim of the article is to identify the main determinants of the development of 'green logistics' in small and medium-sized enterprises in Poland.

\section{Green Logistics in Business Operations}

The early 1990s are considered to be the beginning of the development of the 'green logistics' concept. It was a period of growing social awareness of and responsibility for problems concerning global warming and environmental pollution (Murphy et al. 1996). Undoubtedly, one of the important impulses that gave rise to the development of the 'green logistics' concept was the development of the idea of sustainable development. To date, some authors believe that 'green logistics' is used to implement the assumptions of the concept of sustainable development (Rong 2011; Guirong et al. 2012; Bajdor 2012; Kumar 2015; Hove-Sibanda et al. 2018). This is due to the fact that the goals set for 'green logistics' fit into the goals of the concept of sustainable development, being a response to problems related to the degradation of the natural environment in the area of implemented logistics processes. In the opinion of McKinnon et al. (2015), 'green logistics' is a form of logistics which is expected to not only be environmentally, but often socially, friendly and economically functional. According to the author, 'green logistics' is a concept for managing the flow of material and the accompanying flow of information, starting from the design stage, in such a way that the ecological, social and economic goals of the organisation can be achieved.

1 A similar view in the context of green solutions in SMEs is expressed by: (Mala, Musova 2015; HoveSibanda et al. 2018; Ivanova 2020). 
Although over 25 years have passed since the first mention of 'green' practices in the context of applied logistics processes, the concept of 'green logistics' is still poorly recognised in a wide range of enterprises. In many cases, the reason for this is the lack of managers' knowledge about the assumptions of the concept itself, but also about its implementation methods (Zowada 2018). In order to facilitate the application of 'green' solutions in economic practice, the literature on the subject indicates four stages of 'green logistics' development in business operations (Figure 1).

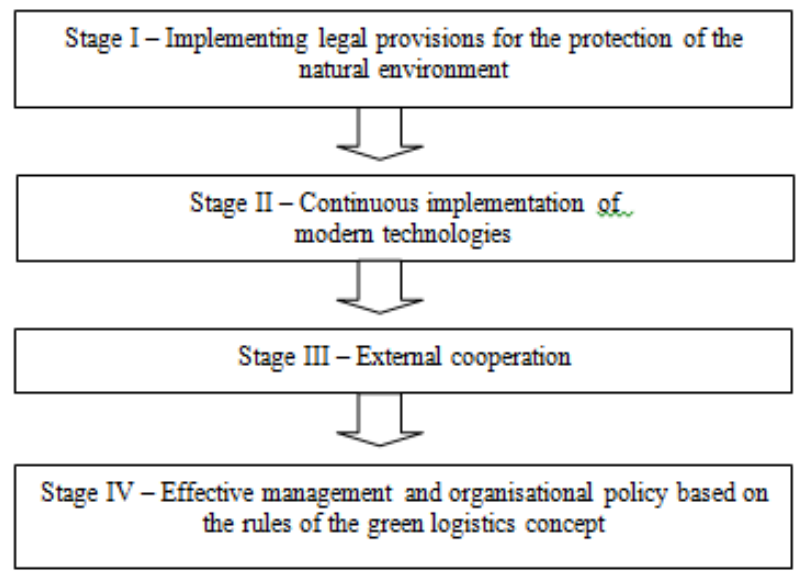

Figure 1. Stages of green logistics development in business operations

Source: (Sarkis et al. 2004; V asiliauskas et al. 2013).

In the first stage of the development of 'green logistics', the implementation of existing legal provisions regarding environmental protection is postulated in the operations of enterprises. If the process of implementing the above-mentioned concept ends at this stage, it is said that the company has adopted a reactive attitude, and thus has reached a certain minimum, which it was most likely mandated to fulfil. Undertaking actions concerning the continuous implementation of modern technologies, and thus realising the assumptions of the second stage, increases the degree of the 'greening' of the enterprise. The author is referring to, for example, IT solutions which enable better use of the company's vehicle fleet, more efficient management of warehouse space, etc. These solutions also include modern transportation and propulsion technologies (lowemission vehicle engines that meet the highest standards of permissible emissions, for example). Therefore, it be said that the development of 'green logistics' in business operations is not possible without investment in modern technologies.

In the third stage, it was highlighted that one cannot speak of a high level of 'greening' of an enterprise without the cooperation of external entities. In practice, many logistics processes are incorporated with the participation of at least two subsequent links in the supply chain: for example, the implementation of a new distribution system or a new concept for the supply system. According to van Hoek (1999), 'green logistics' implemented at company level is often no longer enough, as it is necessary to adopt the perspective of the entire supply chain. For example, the packaging design for a specific product will translate into the needs and possibilities for the effective use of storage 
space or vehicle loading surfaces in all subsequent links in the supply chain. Moreover, the choice of material from which the packaging will be made will influence the way it will be managed after the expiration of its useful life for the end user.

The last stage of development of 'green logistics' is associated with the broad adaptation of green principles in a company's operations. In this case, the assumptions of the concept of green logistics become part of the overall management processes enforced in the company, allowing the highest level of 'greening' to be achieved (Zowada, Niestroj 2019).

In the context of the purpose of this article, one can ask the question about what, in Poland, determines that small and medium-sized enterprises achieve the next stages of the development of 'green logistics' in their activities?

\section{Methodology}

On the basis of world literature review, it was concluded that within the set of potential determinants of 'green logistics' development, the influence can be found of different SMEs' stakeholder groups who have been motivated by, already achieved or just assumed the environmental and economic effects of 'green logistics' (Sarkis et al. 2011; Lau 2011; Zhang et al. 2014; Abdullah et al. 2018). However, the question arises which group (or groups) of stakeholders has the strongest influence on the development of 'green logistics' in SMEs in Poland and what are the reasons for this influence?

In order to answer the above question, a survey was conducted in June and July 2017 in a group of 200 such enterprises operating in Poland. Invitations to participate in the study were sent to SME owners and managers by employees of the Research and Knowledge Transfer Centre at the University of Economics in Katowice using an electronic version of the online questionnaire.

Due to the inability to conduct a random selection for financial and organisational reasons, it was decided to use one of the most well-known and popular types of nonrandom selection - recommended by A. Sagan (2016) - namely quota selection, the application of which requires knowledge of the structure of the general population in terms of the control variables which define this structure. In this case, the number of individual subgroups distinguished on the basis of the selected control variables is proportional to their number in the general population. In other words, based on the available data, the structure of the general population of small and medium-sized enterprises operating in Poland was reflected in the quantified sample. It should be added that the selection of the sample in a quantitative manner was made on the basis of combined characteristics. This means that, taking into account the size of the enterprise expressed by the number of employees and the dominant type of business according to the PKD (Polish Classification of Businesses), the sample reflects the structure of the general population of small and medium-sized enterprises operating in Poland, which takes into account the proportions between the subgroups of enterprises distinguished on the basis of these two characteristics. As a consequence, 157 small and 43 mediumsized enterprises representing all provinces in Poland were included in the examined group of enterprises. 


\section{Research Result and Discussion}

In the understanding of stakeholder theory, the actions taken by an enterprise can be caused by the influence of various stakeholder groups. In this sense, the implementation of solutions proposed under the 'green logistics' concept is the effect of the impact of specific stakeholder groups on these enterprises. Based on the literature analysis, groups of potential stakeholders of small and medium-sized enterprises operating in Poland have been identified:

- government and public administrations as well as other legislative institutions (e.g. $\mathrm{EU})$,

- NGOs and lobbyists,

- society,

- suppliers,

- competitors,

- supply chain leader,

- clients,

- logistics service providers,

- owners,

- managers,

- employees,

- others.

Figure 2 presents the results of the research on the impact of the identified groups of stakeholders on the development of 'green logistics' in the surveyed enterprises.

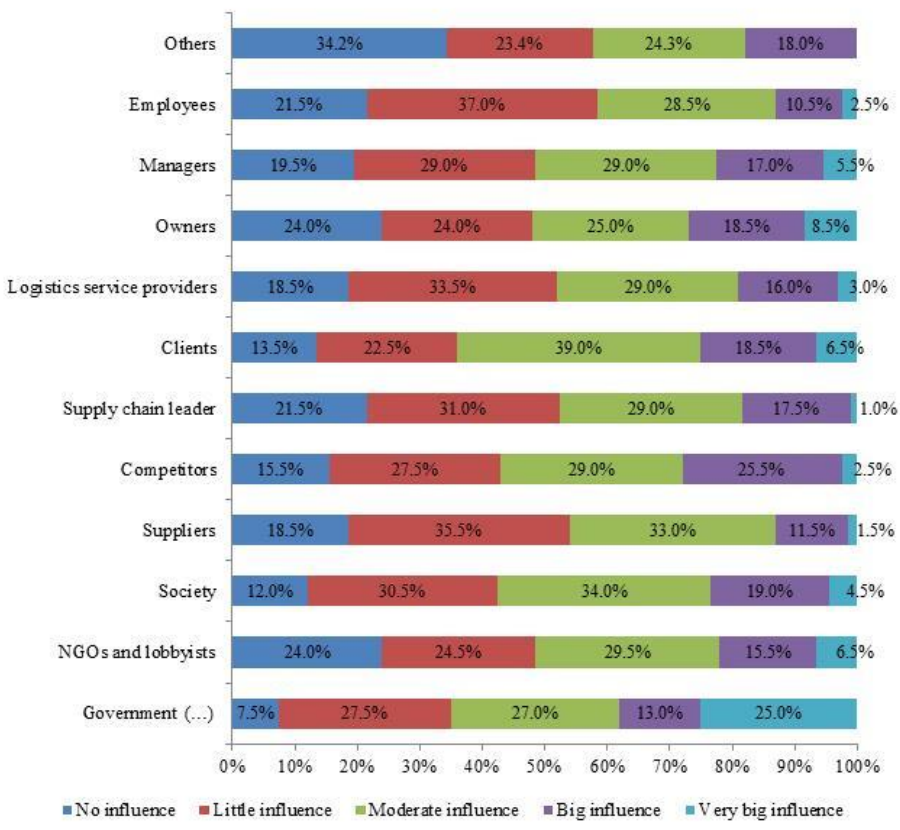

Figure 2. The impact of stakeholders on the development of 'green logistics' in the surveyed enterprises Source: own research 
According to the respondents' declarations, the government, public administration and other legislative institutions have the greatest impact on the development of 'green logistics' in their enterprises. To ensure the cognitive value of the results obtained, a reliability analysis was carried out using the Cronbach's alpha coefficient (the calculated coefficient was 0.847 ), which showed a high consistency between the responses of the respondents regarding the assessment of the impact of individual stakeholder groups on the development of 'green logistics' in their enterprises. In other words, it means that the way the respondents assess the impact of individual stakeholder groups was similar, and thus the results obtained can be considered less accidental.

The results obtained mean that the activities of the surveyed small and medium-sized enterprises regarding environmental protection in the field of logistics processes are to the greatest extent determined by applicable normative acts. This situation is due to two important reasons. First of all, regulations generated by the government, public administration and other legislative institutions in the form of normative acts are generally applicable and often provide for sanctions in the event of non-compliance (in this respect, provisions relating to transport and waste management, including packaging waste, may be indicated). In the case of small and medium-sized enterprises, the preventive importance of any sanctions is particularly important, as possible financial penalties may result in the loss of the liquidity of the enterprise or even the need to cease its operations. Secondly, legal provisions are oriented to obtaining effects on a macro scale. This means that the effects of actions taken by the government, public administration and other legislative institutions, from the point of view of individual enterprises, are not noticeable. The research did not show a statistically significant relationship between the impact of the government and public administration as well as other legislative institutions on the development of 'green logistics' in the surveyed enterprises and the individual ecological and economic effects of the development of 'green logistics' in these enterprises (Table 1). As a consequence, the owners and managers of small and medium-sized enterprises, who are not experiencing the benefits of implementing 'green' solutions, usually do not plan to develop them further in their enterprises, and thus do not go on to the next stages of the development of 'green logistics' (in the group of surveyed small and medium-sized enterprises, the majority of respondents declared that the companies they represent are at one of the first two stages of development of 'green logistics' - over $75 \%$ of the surveyed enterprises).

Table 1. The influence of stakeholders vs the economic and ecological effects of 'green logistics' - Spearman's rho

\begin{tabular}{|l|c|c|c|c|c|c|c|c|c|c|}
\hline \multirow{2}{*}{$\begin{array}{l}\text { Stakeholders influence / } \\
\text { ecological and economic } \\
\text { effects }\end{array}$} & \multicolumn{4}{|c|}{ Ecological effects } & \multicolumn{4}{|c|}{ Economic effects } \\
\cline { 2 - 11 } & E.1 & E.2 & E.3 & E.4 & E.5 & E.6 & E.7 & E.8 & E.9 & E.10 \\
\hline $\begin{array}{l}\text { Government and other } \\
\text { institutions }\end{array}$ & 0.076 & -0.129 & -0.112 & $-0.190^{* *}$ & -0.134 & -0.135 & 0.052 & 0.073 & 0.105 & -0.063 \\
\hline NGOs and lobbyists & $0.251^{* *}$ & $0.263^{* *}$ & $0.327^{* *}$ & $0.256^{* *}$ & $0.312^{* *}$ & $0.317^{* *}$ & $0.247^{* *}$ & $0.249^{* *}$ & $0.205^{* *}$ & $0.317^{* *}$ \\
\hline Society & $0.341^{* *}$ & $0.211^{* *}$ & $0.143^{*}$ & $0.234^{* *}$ & $0.191^{* *}$ & $0.311^{* *}$ & $0.193^{* *}$ & $0.338^{* *}$ & $0.266^{* *}$ & $0.190^{* *}$ \\
\hline Suppliers & $0.374^{* *}$ & $0.265^{* *}$ & $0.322^{* *}$ & $0.289^{* *}$ & $0.353^{* *}$ & $0.364^{* *}$ & $0.290^{* *}$ & $0.338^{* *}$ & $0.294^{* *}$ & $0.318^{* *}$ \\
\hline Competitors & $0.271^{* *}$ & 0.135 & $0.205^{* *}$ & 0.120 & $0.217^{* *}$ & $0.215^{* *}$ & 0.129 & $0.326^{* *}$ & $0.285^{* *}$ & $0.218^{* *}$ \\
\hline Supply chain leader & $\mathbf{0 . 3 8 5}^{* *}$ & $\mathbf{0 . 3 4 8 ^ { * * }}$ & $\mathbf{0 . 3 4 7 ^ { * * }}$ & $\mathbf{0 . 3 4 7 ^ { * * }}$ & $\mathbf{0 . 3 5 1 ^ { * * }}$ & $\mathbf{0 . 4 7 7 ^ { * * }}$ & $\mathbf{0 . 3 0 4}^{* *}$ & $\mathbf{0 . 4 6 1} \mathbf{1}^{* *}$ & $\mathbf{0 . 4 2 4}^{* *}$ & $\mathbf{0 . 4 1 2 ^ { * * }}$ \\
\hline Clients & $0.198^{* *}$ & $0.173^{*}$ & $0.151^{*}$ & $0.179^{*}$ & $0.257^{* *}$ & $0.310^{* *}$ & $0.219^{* *}$ & $0.336^{* *}$ & $0.301^{* *}$ & $0.192^{* *}$ \\
\hline
\end{tabular}




\begin{tabular}{|c|c|c|c|c|c|c|c|c|c|c|}
\hline \multirow{2}{*}{$\begin{array}{l}\text { Stakeholders influence / } \\
\text { ecological and economic } \\
\text { effects }\end{array}$} & \multicolumn{6}{|c|}{ Ecological effects } & \multicolumn{4}{|c|}{ Economic effects } \\
\hline & E.1 & E.2 & E.3 & E. 4 & E. 5 & E.6 & E.7 & E. 8 & E.9 & E.10 \\
\hline Logistics service providers & $0.355^{* *}$ & $0.265^{* *}$ & $0.368^{* *}$ & $0.360^{* *}$ & $0.336^{* *}$ & $0.447^{* *}$ & $0.362^{* *}$ & $0.369^{* *}$ & $0.330^{* *}$ & $0.420^{* *}$ \\
\hline Own & $0.464^{* *}$ & $0.385^{* *}$ & $0.426^{* *}$ & $0.335^{* *}$ & $0.337^{* *}$ & $0.491^{* *}$ & $0.347^{* *}$ & $0.541^{* *}$ & 0.486 & $0.473^{* *}$ \\
\hline Man & $0.450^{* *}$ & $0.379^{* *}$ & $0.441^{* *}$ & $0.378^{* *}$ & $0.380^{* *}$ & $0.451^{* *}$ & $0.381^{* *}$ & $0.469^{* *}$ & $0.398^{* *}$ & $0.457^{* *}$ \\
\hline Employees & $0.337^{* *}$ & $0.229^{* *}$ & $0.327^{* *}$ & $0.300^{* *}$ & $0.274^{* *}$ & $0.406^{* *}$ & $0.295^{* *}$ & $0.373^{* *}$ & $0.268^{* *}$ & $0.341^{* *}$ \\
\hline Others & $0.397^{* *}$ & $0.416^{* *}$ & $0.499^{* *}$ & $0.570^{* *}$ & $0.473^{* *}$ & $0.533^{* *}$ & $0.346^{* *}$ & $0.390^{* *}$ & $0.285^{* *}$ & $0.586^{* *}$ \\
\hline
\end{tabular}

** correlation significant at the level of $0.01 ; *$ correlation significant at the level of 0.05

E.1 - reduction of the amount of waste generated (e.g. packaging), E. 2 - reduction of $\mathrm{CO}_{2}$ emissions, E.3 reduction of emissions of other harmful substances, E. 4 - reduction of emitted noise, E. 5 - increase in energy efficiency, E.6 - reduction of the scale of consumption of natural resources, E.7 - reduction of costs of implemented logistics processes, E.8 - improvement in the company's competitive position, E.9 improvement in the company's image, E.10 - increase in efficiency of implemented logistics processes.

Source: own research

Remaining in the area of the effects obtained from the development of 'green logistics', it should be emphasised that the strongest positive correlation in the group of internal stakeholders of the surveyed enterprises was identified between the impact of owners and managers on the development of 'green logistics' in the surveyed enterprises and the ecological and economic effects of the 'green logistics' achieved by these enterprises. This results from the fact that both of these groups of stakeholders are most interested in achieving measurable effects of the actions undertaken, and moreover they note their occurrence the fastest. Thus, motivated by the effects already achieved, in a direct way (through decisions) and knowing the specifics and capabilities of their enterprises, they continue to develop 'green' solutions. In the case of external stakeholders, the strongest positive correlation was found between the influence of the supply chain leader on the development of 'green logistics' in the surveyed enterprises and the economic and ecological effects of the 'green logistics' achieved by these enterprises, and between the impact of logistics service providers and the mentioned effects. The leader of the supply chain usually pushes for specific solutions aimed at achieving the assumed goals. For example, compared to the influence of the government, public administration and other legislative institutions, the influence of the supply chain leader is focused on solutions that take into account the specificity of a given chain and, above all, are tailored to its needs. In turn, logistics service providers implement 'green' practices in a way that brings the greatest economic and ecological benefits to themselves, but also to their clients.

In the context of the above conclusions, it should be emphasised that the empirical research showed no correlation between the influence of the government, public administration and other legislative institutions and the subsequent stages of the development of 'green logistics' in the surveyed enterprises (Table 2). According to the author, the lack of correlation results from the fact that the generated legal provisions are usually of a general nature and do not take into account the level of advancement of the 'green' solutions used in specific enterprises. Thus, the influence of the government, public administration and other legislative institutions amounts to reaching a certain minimum by enterprises related to the state's environmental policy. According to the knowledge available to the author, there are no types of initiatives or programmes that would encourage small and mediumsized enterprises operating in Poland to be more involved in the development of 'green 
logistics' in their activities, other than those resulting from applicable regulations.

The results of the correlation analysis also showed that in the case of other stakeholder groups, their impact on the development of 'green logistics' in the surveyed enterprises, on average, increases with the transition through these enterprises to the next stages of the development of 'green logistics' (Table 2). This means that as the successive stages of the development of 'green logistics' are overcome, the remaining groups of stakeholders become involved in the processes of the development of 'green logistics' in these enterprises.

Table 2. The influence of stakeholders vs the stages of the development of 'green logistics' - Spearman tho

\begin{tabular}{|l|c|}
\hline $\begin{array}{l}\text { Stakeholder } \\
\text { influence }\end{array}$ & $\begin{array}{c}\text { The stage of the development } \\
\text { of 'green logistics' }\end{array}$ \\
\hline Government and other institutions & 0.044 \\
\hline NGOs and lobbyists & $0.392^{* *}$ \\
\hline Society & $0.258^{* *}$ \\
\hline Suppliers & $0.300^{* *}$ \\
\hline Competitors & $0.223^{* *}$ \\
\hline Supply chain leader & $\mathbf{0 . 4 0 3}^{* *}$ \\
\hline Clients & $0.241^{* *}$ \\
\hline Logistics service providers & $0.266^{* *}$ \\
\hline Owners & $0.324^{* *}$ \\
\hline Managers & $0.271^{* *}$ \\
\hline Employees & $0.165^{*}$ \\
\hline Others & $0.309^{* *}$ \\
\hline$* *$ correlation significant at the level of $0.01 ; *$ correlation significant at the level of 0.05 \\
\hline
\end{tabular}

Source: own research

The strongest statistically significant positive correlation was identified between the impact of the supply chain leader on the development of 'green logistics' in the surveyed enterprises and the stages of the development of 'green logistics' (0.403). The influence of the supply chain leader thus becomes a strong driving force for the implementation of 'green' solutions in the area of implemented logistics processes in those enterprises that are at the higher stages of the development of 'green logistics' in their activities.

\section{Conclusions}

On the basis of conducted research, it was revealed that SMEs' activities related to environment protection when running logistics processes are mostly determined by actual legal provisions. However, this amounts to enterprises reaching a certain minimum related to the state's environmental policy. The basic problem in the case of government regulations is the lack of expected effects of 'green logistics' for small and medium-sized enterprises. General solutions do not bring the desired effects at the micro level. As a result, most enterprises, without experiencing the benefits of implementing 'green' solutions, usually do not plan to develop them further. 
According to the results of the research, the best scenario for the development of 'green logistics' in small and medium-sized enterprises is the cooperation of owners and managers with the leaders of the supply chains. As the research results have shown, these are the groups of stakeholders for which the strongest feedback occurs between their impact on the activities undertaken in the implementation of 'green logistic' practices, and the economic and ecological effects obtained. In this case, the actions taken in the field of development of 'green logistics' are a natural consequence of the increase in the degree of integration of supply chain participants, which is the result of assumed business goals and not imposed legal regulations.

\section{References}

Abdullah, M.I., Sarfraz, M., Qun, W., Javaid, N. (2018). Drivers of green supply chain management, LogForum 14(4), p. 446, DOI 10.17270/J.LOG.2018.297.

Bajdor, P. (2012). Comparison between sustainable development concept and green logistics - the literature review, Polish Journal of Management Studies, Vol. 5.

Chen, X., Jiang, L., Wang, Ch. (2011). Business Process Analysis and Implementation Strategies of Greening Logistics in Appliances Retail Industry, Energy Procedia 5, p. 333.

Cosimato, S., Troisi, O. (2014). The Influence of Green Innovation in Logistics Competitiveness and Sustainability. The DHL Case Study, 17th Toulon-Verona International Conference Excellence in Services, Conference Proceedings, Liverpool John Moores University, August 28-29, p. 97.

Guirong, Z., Qing, G., Bo, W., Dehua, L. (2012). Green logistics and Sustainable development, 2012 International Conference on Information Management, Innovation Management and Industrial Engineering, IEEE, p. 132.

van Hoek, R.I. (1999). From reversed logistics to green supply chains, Supply Chain Management: An International Journal, Vol. 4, No. 3, p. 133.

Hove-Sibanda, P., Sibanda, K. \& Mukarumbwa, P., (2018). Greening up in logistics: Managerial perceptions of small and medium-sized enterprises on sustainability in Zimbabwe, The Journal for Transdisciplinary Research in Southern Africa 14(1), https://doi.org/10.4102/td.v14i1.559.

Ivanova, T. (2020). Management of Green Procurement in Small and Medium-Sized Manufacturing Enterprises in Developing Economies. Amfiteatru Economic, 22(53), DOI 10.24818/EA/2019/53/121.

Kumar, A. (2015). Green Logistics for sustainable development: an analytical review, IOSRD, International Journal of Business, Vol. 1, Iss. 1, April, pp. 8-11.

Lau, K.H. (2011). Benchmarking green logistics performance with a composite index, Benchmarking: An International Journal, Vol. 18, No. 6, p. 890.

Mala D., Musova Z. (2015). Perception of implementation processes of green logistics in SMEs in Slovakia, Procedia Economics and Finance 26.

McKinnon, A., Brown, M., Piecyk, M., Whiteing, A. (2015). Green Logistics. Improving the Environmental Sustainability of Logistics, Third edition, Kogan Page Limited, London.

Murphy, P.R., Poist, R.F., Braunschweig, Ch.D. (1996). Green logistics: comparative views of environmental progressives, moderates, and conservatives, Journal of Business Logistics, Vol. 17, No. 1, p. 192.

Rong, C. (2011). Green Logistics Research Based on Sustainable Development, Artificial Intelligence, Management Science and Electronic Commerce (AIMSEC), IEEE, pp. 4635-4639.

Sagan, A. (2016). Metodologia badań ekonomicznych, Wydawnictwo Uniwersytetu Ekonomicznego w Krakowie, Kraków, s. 171.

Sarkis, J., Meade, L.M., Talluri, S. (2004). E-logistics and the natural environment, Supply Chain Management. An International Journal, Vol. 9(4), pp. 310-311.

Sarkis, J., Zhu, Q., Lai, K. (2011). An organizational theoretic review of green supply chain management literature, Int. J. Production Economics 130.

Srivastava, S.K. (2007). Green supply-chain management: a state-of-the-art literature review, International Journal of Management Reviews, 9 (1). 
Vasiliauskas, A.V., Zmkevičiüté, V., Šimonyte, E. (2013). Implementation of the concept of green logistics referring to IT applications for road freight transport enterprises, Business: Theory and Practice, Vol. 14(1), p. 45.

Zhang, Y., Thompson, R.G., Bao, X., Jiang, Y. (2014). Analyzing the Promoting Factors for Adopting Green Logistics Practices: A Case Study of Road Freight Industry in Nanjing, China, Procedia - Social and Behavioral Sciences 125, pp. 433-438.

Zowada, K. (2018). Environmental responsibility in logistics activities of small and medium-sized enterprises, Research Journal of the University of Gdańsk. Transport Economics and Logistics, vol. 78, pp. 157-166, https://doi.org/10.26881/etil.2018.78.13.

Zowada, K., Niestrój, K. (2019). Cooperation of small and medium-sized enterprises with other supply chain participants in implementing the concept of green logistics, Research Papers of Wroclaw University of Economics, Vol. 63, No. 6, pp. 252-253, https://doi.org/10.15611/pn.2019.6.20. 